\title{
XXXVIII. On the conversion of the solid ferrocyanide of potassium into the sesqui- ferrocyanide
}

\section{C.F. Schœnbein}

To cite this article: C.F. Schœnbein (1846) XXXVIII. On the conversion of the solid ferrocyanide of potassium into the sesqui-ferrocyanide, Philosophical Magazine Series 3, 28:186, 211-211, DOI: $10.1080 / 14786444608645399$

To link to this article: http://dx.doi.org/10.1080/14786444608645399

曲 Published online: 30 Apr 2009.

Submit your article to this journal $\sqsubset$

Џll Article views: 2

Q View related articles ๘ 
XXXVIII. On the Conversion of the solid Ferrocyanide of Potassium into the Sesqui-ferrocyanide. By C. F. SchaenBEIN*.

$\mathrm{N}$ a former notice $\mathrm{I}$ have shown that a solution of the yellow prussiate of potash in water, placed in contact with an atmosphere of ozone, instantaneously destroys the latter, and is converted into the red sesqui-ferrocyanide. Since that communication was made I have ascertained that even the solid yellow salt very readily absorbs ozone and is changed into the red one. If a crystal of the common prussiate is suspended in a balloon containing an atmosphere strongly charged with ozone, and kept in that state by means of phosphorus and water, it will soon assume the colour peculiar to the red cyanide, just in the same way as it would do when held in air containing chlorine. The surface of the crystal, after having remained in the ozonized air for about twelve hours, is changed into the red salt, which may be easily separated from the yellow nucleus by mechanical means. A crystal of about a cubic inch in bulk appeared after thirtysix hours' suspension in ozonized air covered with a crust of the red cyanide, at least one line thick; and in another case I saw a smaller crystal of the yellow salt entirely converted into the red one. I hardly need say that by changing the yellow compound into the sesqui-ferrocyanide, the cohesive state of the former undergoes a material alteration. The red crust surrounding the yellow nucleus is rather brittle, and consists of a heap of small crystals of the sesqui-ferrocyanide. It is worthy of remark, that under the circumstances mentioned the yellow prussiate becomes moist, and exhibits in that state a very strong alkaline reaction.

XXXIX. On the Decomposition of the Yellow and Red Ferrocyanides of Potassium by Solar Light. By C. F. SchasBEIN*.

A SOLUTION of the yellow prussiate of potash kept in $A$ the dark does not change its colour, but when exposed to the action of solar light it becomes of a deeper yellow, To render that change very perceptible, a weak, $i$, e. nearly colourless, solution must be used, in which case the liquid will assume a yellow colour after having been acted upon by strong sunlight only for a few minutes. If the bottle containing the solution be closed and not quite filled with the liquid, an odour of prussic acid is perceptible, and at the same time

- Communicated by the Author.

Q 2 